\title{
Effects of high-intensity interval training on cardiometabolic health: a systematic review and meta-analysis of intervention studies
}

\author{
Romeo B Batacan Jr, ${ }^{1,2}$ Mitch J Duncan, ${ }^{3}$ Vincent J Dalbo, ${ }^{1,4}$ Patrick S Tucker, ${ }^{1,4}$ \\ Andrew S Fenning ${ }^{1,2}$
}

- Additional material is published online only. To view please visit the journal online (http://dx.doi.org/10.1136/ bjsports-2015-095841)

'School of Medical and Applied Sciences, Central Queensland University, Rockhampton,

Queensland, Australia ${ }^{2}$ Centre for Physical Activity Studies, Central Queensland University, Rockhampton, Queensland, Australia

${ }^{3}$ Faculty of Health and Medicine, School of Medicine \& Public Health, Priority Research Centre for Physical Activity and Nutrition, The University of Newcastle, University

Drive, Callaghan, Queensland, Australia

${ }^{4}$ Clinical Biochemistry Laboratory, Central Queensland University, Rockhampton, Queensland, Australia

Correspondence to Dr Andrew S Fenning, School of Medical and Applied Sciences, Central Queensland University, Rockhampton, QLD 4702,

Australia;

a.fenning@cqu.edu.au

Accepted 3 October 2016 Published Online First 20 October 2016

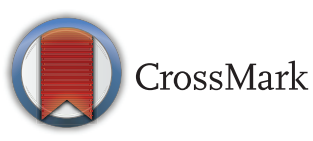

To cite: Batacan RB, Duncan MJ, Dalbo VJ, et al. Br I Sports Med 2017:51:494-503.

\section{ABSTRACT}

The current review clarifies the cardiometabolic health effects of high-intensity interval training (HIIT) in adults. A systematic search (PubMed) examining HIIT and cardiometabolic health markers was completed on 15 October 2015. Sixty-five intervention studies were included for review and the methodological quality of included studies was assessed using the Downs and Black score. Studies were classified by intervention duration and body mass index classification. Outcomes with at least 5 effect sizes were synthesised using a random-effects meta-analysis of the standardised mean difference (SMD) in cardiometabolic health markers (baseline to postintervention) using Review Manager 5.3. Short-term (ST) HIIT ( $<12$ weeks) significantly improved maximal oxygen uptake $\left(\mathrm{VO}_{2}\right.$ max; SMD $0.74,95 \% \mathrm{Cl}$ 0.36 to $1.12 ; p<0.001$ ), diastolic blood pressure (DBP; SMD $-0.52,95 \% \mathrm{Cl}-0.89$ to $-0.16 ; \mathrm{p}<0.01)$ and fasting glucose (SMD $-0.35,95 \% \mathrm{Cl}-0.62$ to -0.09 ; $\mathrm{p}<0.01)$ in overweight/obese populations. Long-term (LT) HIIT ( $\geq 12$ weeks) significantly improved waist circumference (SMD $-0.20,95 \% \mathrm{Cl}-0.38$ to -0.01 ; $\mathrm{p}<0.05), \%$ body fat $(\mathrm{SMD}-0.40,95 \% \mathrm{Cl}-0.74$ to $-0.06 ; p<0.05), \mathrm{VO}_{2} \max (\mathrm{SMD} 1.20,95 \% \mathrm{Cl} 0.57$ to 1.83; $p<0.001)$, resting heart rate (SMD $-0.33,95 \%$ $\mathrm{Cl}-0.56$ to $-0.09 ; p<0.01)$, systolic blood pressure (SMD $-0.35,95 \% \mathrm{Cl}-0.60$ to $-0.09 ; p<0.01)$ and DBP (SMD $-0.38,95 \% \mathrm{Cl}-0.65$ to $-0.10 ; \mathrm{p}<0.01$ ) in overweight/obese populations. HIIT demonstrated no effect on insulin, lipid profile, $\mathrm{C}$ reactive protein or interleukin 6 in overweight/obese populations. In normal weight populations, ST-HIIT and LT-HIIT significantly improved $\mathrm{VO}_{2}$ max, but no other significant effects were observed. Current evidence suggests that ST-HIIT and LT-HIIT can increase $\mathrm{VO}_{2}$ max and improve some cardiometabolic risk factors in overweight/obese populations.

\section{INTRODUCTION}

The $\mathrm{WHO}^{1}$ and the American College of Sports Medicine (ACSM) $)^{2}$ recommend at least $150 \mathrm{~min}$ of moderate-intensity physical activity $(40-60 \%$ maximum oxygen uptake $\left.\left(\mathrm{VO}_{2} \max \right)^{3}\right)$ or $75 \mathrm{~min}$ of vigorous-intensity physical activity $(60-85 \%$ $\left.\mathrm{VO}_{2} \max \right)$ per week for healthy adults to maintain or improve health. Despite the established therapeutic potential of moderate-intensity to vigorous-intensity physical activity, $31.1 \%$ of the adult worldwide (43\% US population) fails to meet the minimum physical activity guidelines. ${ }^{4}$ Frequently cited barriers to engagement in physical activity are lack of time, low motivation and poor adherence. $^{5} 6$ To this end, several investigators ${ }^{7-9}$ have examined the efficacy of high-intensity interval training (HIIT; $\geq 85 \% \mathrm{VO}_{2} \max ^{3}$ ) to maintain or improve health as an alternative to longer duration, continuous, moderate-intensity to vigorousintensity physical activity approaches recommended by the WHO and ACSM. One of the primary advantages of HIIT, compared to lesser-intensity exercise, is that HIIT requires less time be spent exercising, while providing similar or greater health-related benefits, compared to established physical activity recommendations. ${ }^{10}{ }^{11}$ As a result, it has been theorised that HIIT can mitigate the most commonly cited barrier to physical activity which is 'lack of time'. 56

Interval training refers to intermittent exercise that involves alternating short bursts of higherintensity activity with lower-intensity activity for recovery or rest. ${ }^{3}{ }^{12}$ HIIT is an enhanced form of interval training involving brief, high-intensity, anaerobic exercise (ranging from $85 \%$ to $250 \%$ $\mathrm{VO}_{2}$ max for $6 \mathrm{~s}$ to $4 \mathrm{~min}$ ) separated by brief, but slightly longer bouts of low-intensity aerobic rest (ranging from $20 \%$ to $40 \% \mathrm{VO}_{2}$ max for $10 \mathrm{~s}$ to 5 min). ${ }^{13}$ Numerous studies have demonstrated greater health-related benefits from HIIT compared to traditional moderate-intensity continuous training (MICT). ${ }^{14-17}$ Compared with MICT, HIIT has been reported to more effectively increase aerobic capacity $\left(\mathrm{VO}_{2} \max \right)^{14-17}$ and reduce risk factors associated with metabolic syndrome, including blood pressure (BP),${ }^{17}$ insulin action ${ }^{16}$ and lipogenesis, ${ }^{16}$ in a variety of patient populations. Recent systematic reviews and meta-analyses have reported HIIT, compared to MICT, can significantly increase peak oxygen uptake in individuals with lifestyleinduced cardiometabolic diseases ${ }^{18}$ and to stimulate modest improvements in $\mathrm{VO}_{2}$ max compared to pretraining values in active non-athletic and sedentary individuals. ${ }^{19}$

As such, HIIT is a promising method by which to reduce cardiometabolic risk factors. ${ }^{20}$ However, reviews of HIIT, compared to MICT, to date have focused on cardiorespiratory fitness ${ }^{18} 1921$ and vascular function. ${ }^{22} \mathrm{~A}$ single meta-analysis ${ }^{23}$ of six studies examined the effect of HIIT on traditional cardiovascular disease (CVD) risk factors in individuals with cardiometabolic disorders and found HIIT and MICT to have similar effects on metabolic risk factors (body composition, BP, lipid profile and glucose). However, no review, to date, has sought to provide an extensive review of the effect of HIIT on traditional and novel markers of 
CVD risk factors such as inflammation. The need for a systematic review/meta-analysis examining the efficacy of HIIT on markers of cardiometabolic health is particularly relevant as a growing number of individuals who develop CVD, despite the absence of traditional CVD risk factors (ie, hypertension, elevated blood glucose and high cholesterol). ${ }^{24}$ Additionally, the higher exertion and unique pattern of HIIT may induce changes in novel markers of CVD risk. For example, high-intensity exercise has been shown to reduce disease-related inflammation (interleukin 6 (IL-6) and tumour necrosis factor (TNF)- $\alpha$ ) in animals. ${ }^{25}$ Therefore, to further examine the potential benefit of HIIT, this study will include novel markers of CVD risk which previous reviews have not examined.

Therefore, we conducted a systematic review and meta-analysis to synthesise the effects of HIIT on cardiometabolic health markers, including body mass, waist circumference (WC), hip circumference (HC), body mass index (BMI), waist-to-hip ratio (WHR), \% body fat, resting heart rate (HR), $\mathrm{BP}, \mathrm{VO}_{2}$ max, fasting glucose, glycosylated haemoglobin, insulin, total cholesterol, low-density lipoprotein (LDL) cholesterol, high-density lipoprotein (HDL) cholesterol, triglycerides, C reactive protein (CRP), IL-6, TNF- $\alpha$, TNF receptor-1 (TNFR1) and TNF receptor-2 (TNFR2) in adults.

\section{METHODS}

A systematic search of clinical trials, randomised controlled trials, controlled clinical trials and comparative studies was initially performed on 25 March 2015 and completed on 15
October 2015 based on the PRISMA guidelines ${ }^{26}$ following the protocol of a systematic review on physical activity. ${ }^{27}$ Articles were retrieved from PubMed using the following search criteria: (high intensity interval training OR high-intensity interval training OR high intensity interval exercise OR high-intensity interval exercise OR high intensity intermittent exercise OR high-intensity intermittent exercise OR sprint interval training OR HIIT OR HIIE) AND (fasting plasma glucose OR glycosylated hemoglobin OR HbA1c OR triglycerides OR insulin OR total cholesterol OR LDL cholesterol OR HDL cholesterol OR CRP OR C-reactive protein OR IL-6 OR interleukin-6 OR TNF-alpha OR TNF receptor-1 OR TNFR1 OR TNF receptor-2 OR TNFR2 OR 'body mass index' OR BMI OR waist circumference OR hip circumference OR waist-to-hip ratio OR resting heart rate OR per cent body fat OR lean body mass OR resting blood pressure OR maximum heart rate OR $\mathrm{VO}_{2}$ max) AND Humans[MeSH] AND Adult[MeSH] AND English[lang].

Initially, titles and abstracts of identified articles were checked for relevance by two reviewers (RBB and PST). Subsequently, the reviewers independently reviewed the full text of potentially eligible papers. Any disagreement between the reviewers for inclusion was resolved through discussion. Additional articles were identified via hand-searching and reviewing the reference lists of relevant papers. Figure 1 presents the flow of papers through the study selection process.

Studies were considered to be eligible for inclusion according to the following criteria: (1) participants were $\geq 18$ years of age.

Excluded based on title and abstract $(n=138)$

Records identified through

PubMed database searching $(n=212)$

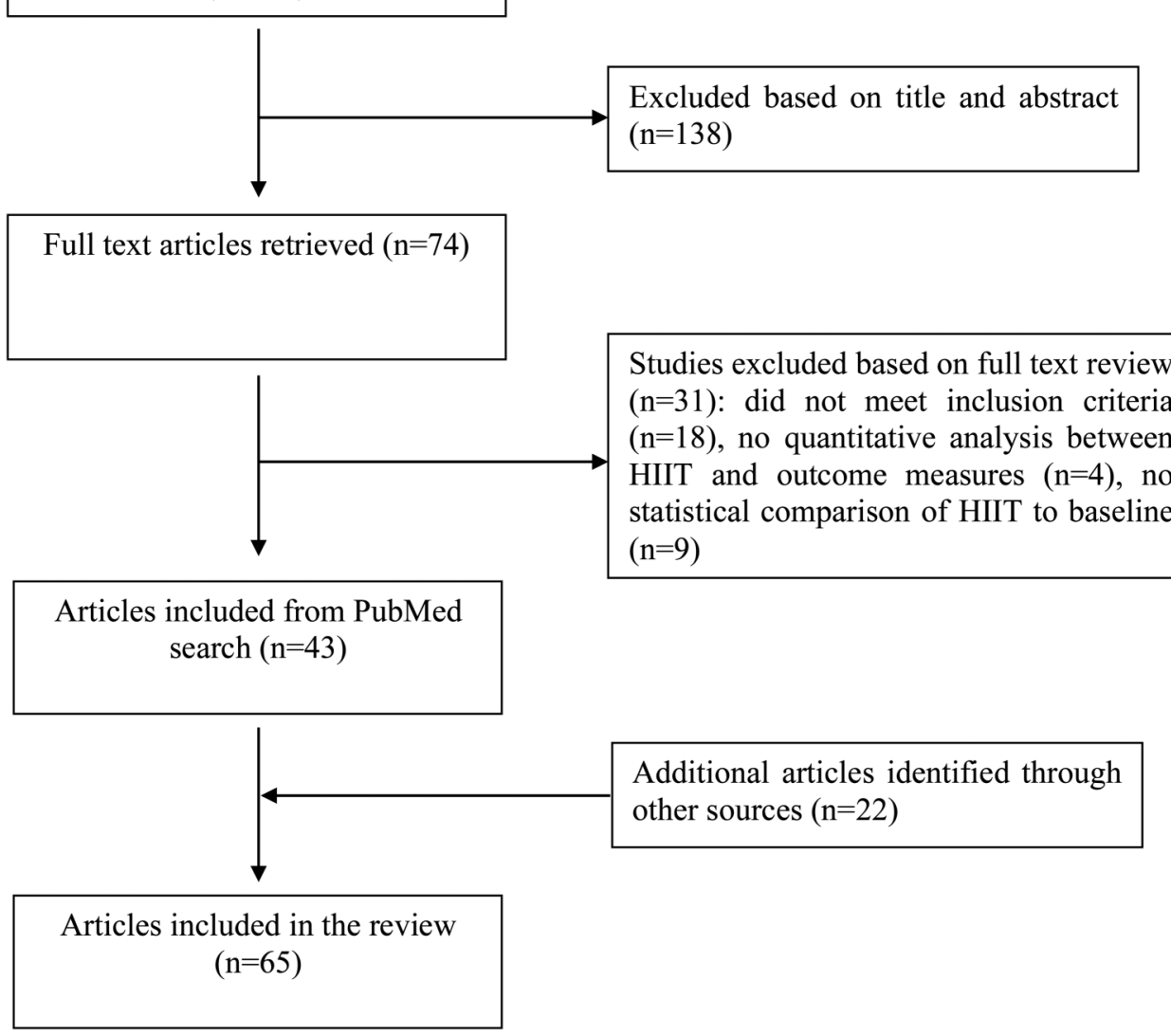

Figure 1 Flow diagram of study selection. HIIT, high-intensity interval training. 
(2) The study examined at least one of the following cardiometabolic health markers in humans: body mass, WC, HC, BMI, WHR, \% body fat, $\mathrm{HR}, \mathrm{BP}, \mathrm{VO}_{2}$ max, fasting glucose, glycosylated haemoglobin, insulin, total cholesterol, LDL cholesterol, HDL cholesterol, triglycerides, CRP, IL-6, TNF- $\alpha$, TNFR1 or TNFR2. (3) The study employed an intervention (randomised or non-randomised) of either short-term (ST-HIIT; $<12$ weeks) or long-term (LT-HIIT; $\geq 12$ weeks) HIIT defined as activities with intermittent bouts of activity that were performed at maximal effort, $\geq 85 \% \mathrm{VO}_{2} \max , \geq 85 \% \mathrm{HR}$ reserve or the relative intensity of at least $90 \%$ HR max. ${ }^{3} 28$ (4) The study included a HIIT session lasting $\leq 4 \mathrm{~min} / \mathrm{set}$ interspersed with an interval of rest or active recovery. (5) The study included quantitative analyses (statistical comparisons of the intervention to baseline/pretraining values) of the effect of HIIT on at least one of the outcome measures mentioned above (criteria ii). (6) The study reported baseline BMI of HIIT participants or baseline BMI can be calculated from the provided data. (7) The article was published or accepted for publication in a refereed journal from 1970 up to the search date. (8) The study was published in English. To differentiate the effect of HIIT duration on cardiometabolic markers, a classification of ST-HIIT ( $<12$ weeks) and LT-HIIT ( $\geq 12$ weeks) based on previous studies ${ }^{2029} 30$ was used in this review.

Two authors (RBB and PST) independently assessed the quality of the studies that met the inclusion criteria (table 1). The risk of bias and strength of evidence from individual studies were assessed using the Downs and Black Checklist, ${ }^{31}$ which uses a scoring system to assess the strength of reporting, external validity, internal validity and statistical power. The maximum score that can be received is 32 . Adapted from another systematic review, ${ }^{32}$ the score obtained by each study was divided by 32 and multiplied by 100 to provide a 'Study Quality Percentage'. Study quality percentages were then classified as high $(66.7 \%$ or higher), fair (between $50.0 \%$ and $66.6 \%)$ and low $(<50.0 \%) .^{32}$

Studies were stratified based on the duration of the training intervention and BMI classification. Mean BMI values were classified as follows: normal weight $\left(18.5-24.99 \mathrm{~kg} / \mathrm{m}^{2}\right)$, overweight $\left(\geq 25-29.99 \mathrm{~kg} / \mathrm{m}^{2}\right)$ and obese $\left(\geq 30 \mathrm{~kg} / \mathrm{m}^{2}\right)$. ${ }^{33}$ For outcome markers examined in five or more studies, a meta-analysis was conducted in Review Manager 5.3 (The Cochrane Collaboration, Copenhagen, Denmark) using the inversevariance statistical method. Previous meta-analyses have applied a minimum of five effect sizes to be included in the meta-analysis. ${ }^{34} 35$ Too few studies of LT-HIIT with normal weight participants were available for meta-analysis. In instances where insufficient statistical information was reported to calculate mean change in health markers (ie, relevant measurements had been taken but the pretraining and post-training values were not reported or were presented in graphs), the authors were contacted and asked to provide the missing data. When no reply was received, the study/outcome was excluded from the meta-analysis. The effect size of the standardised mean difference (SMD) in cardiometabolic health markers from preintervention to postintervention in each study was calculated and pooled using the random-effects model (appropriate for data gathered from the published literature). Effect sizes were quantified as large ( $>0.8 \mathrm{SMD})$, medium (0.5 SMD-0.8 SMD) small (0.2 SMD-0.5 SMD) or non-significant $(<0.2 \text { SMD) })^{36}$ Heterogeneity of included studies was assessed using the $\mathrm{I}^{2}$ statistic with heterogeneity estimates of $25 \%, 50 \%$ and $75 \%$ representing low, moderate and high heterogeneity, respectively. The significance level was set at $\mathrm{p}<0.05$.
Where significant heterogeneity was found, meta-regression was performed using Comprehensive Meta-analysis V.3 (Biostat, New Jersey, USA) in an attempt to determine whether intervention duration, total HIIT time used (min), BMI and baseline level of the outcome variable mediated the observed changes. Total HIIT time was calculated by multiplying session duration (HIIT in minutes $\times$ number of repetitions, maximum repetition was used for studies where range was provided) by the frequency and duration of intervention. Intervention duration, total HIIT time used (min), BMI and baseline levels were used since these factors are likely to impact the outcome variables.

Where meta-analysis is not possible due to insufficient studies, a modified form of coding system described by Sallis et $a l^{37}$ was used to summarise the studies reporting the effect of HIIT on cardiometabolic markers. If $0-33 \%$ of the studies reported a statistically significant difference between HIIT and cardiometabolic markers, the result was categorised as no effect (0). If $34-59 \%$ of the studies reported a statistically significant difference, the result was categorised as inconsistent (?). If 60$100 \%$ of the studies reported a statistically significant difference, the result was rated as positive $(+)$ or negative $(-)$, respective of the direction of the effect. When four or more studies supported a difference or no difference, it was coded as,++-- or 00 to indicate consistent observations. The ?? code indicated a marker that has been examined in four or more studies with inconsistent findings.

\section{RESULTS}

The search identified 212 articles published between the years 1981 and October 2015. Of these, 138 articles were excluded as they were not relevant to the scope of this review. Of the remaining 74 articles, 43 met the inclusion criteria and were included in the review. An additional 22 articles were identified through the reference lists of the included studies. As a result, 65 studies were included in the final analysis.

General study characteristics are summarised in table 1; more detailed study characteristics are presented in online supplementary table S1, and the effects of ST-HIIT and LT-HIIT on cardiometabolic health markers reported in each study are presented in online supplementary tables S2 and S3, respectively. All studies included in this analysis employed a HIIT intervention. The number of study participants in HIIT groups ranged from 5 to 85 . Generally, participants were young (1835 years old) men and women. The HIIT protocols ranged from an acute single session (a single 30 min bout of HIIT) to longer term multiple sessions (four HIIT sessions, lasting 4 min per session, three times per week for 52 weeks). Exercise modalities included treadmill running, swimming and cycling. Nineteen of $65(29 \%)$ studies examined HIIT in participants with a current medical condition (hypertension, diabetes, metabolic syndrome, post myocardial infarction, coronary artery disease and patients who had a transplanted heart). Thirty-seven of $65(57 \%)$ studies examined HIIT in overweight/obese participants, based on BMI. The summary estimates of the effect of ST-HIIT and LT-HIIT on cardiometabolic health variables in normal weight and overweight/obese populations are provided in figures 2 and 3. Forest plots on the effects of ST-HIIT and LT-HIIT on cardiometabolic markers are provided in online supplementary figures S1-S4. Table 2 provides a summary coding of the studies (not included in the meta-analysis) reporting the effect of ST-HIIT and LT-HIIT on cardiometabolic health markers. 


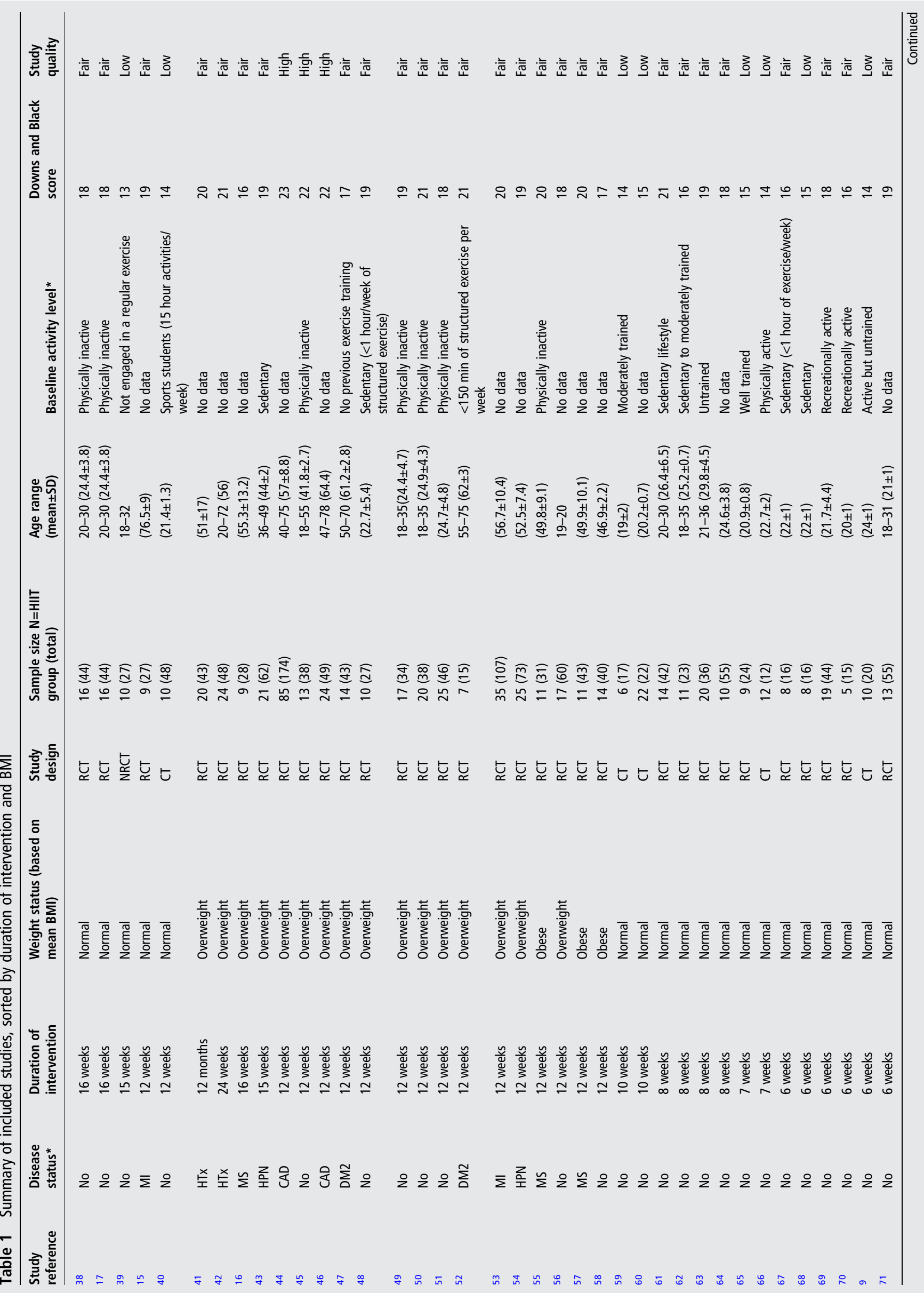




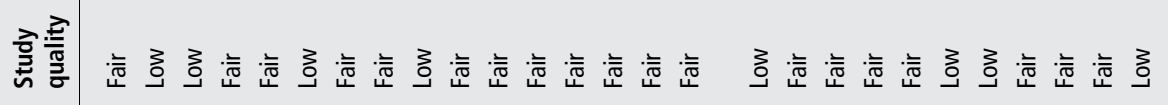

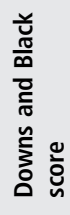

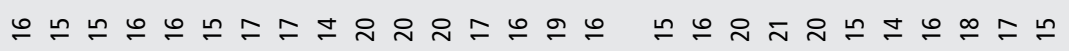

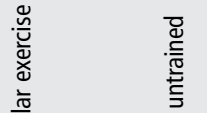

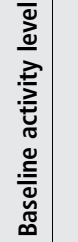

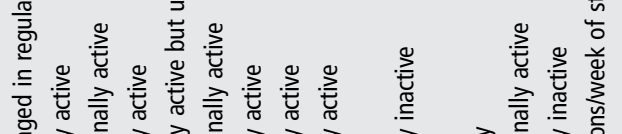

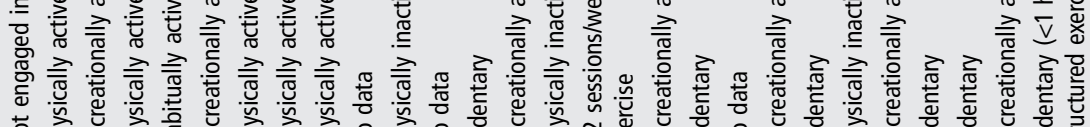

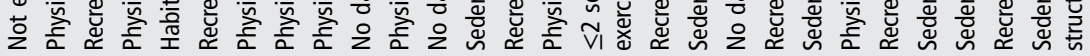

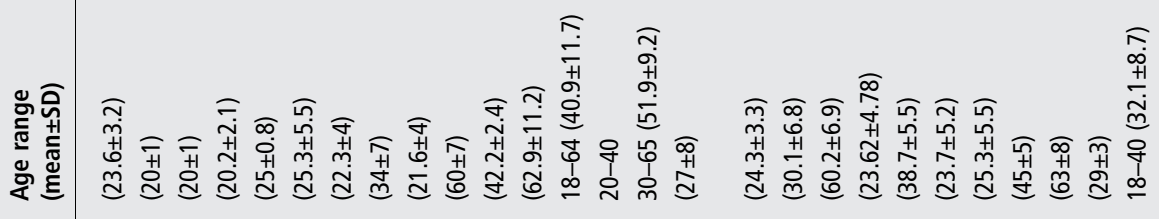

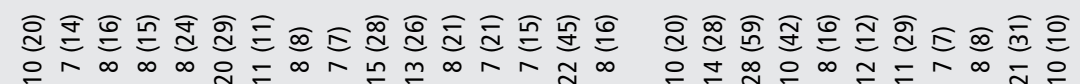

啇

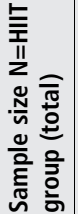

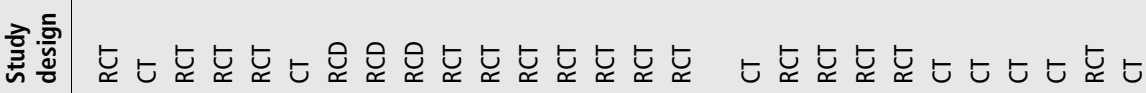

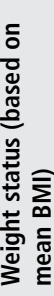

ॠ

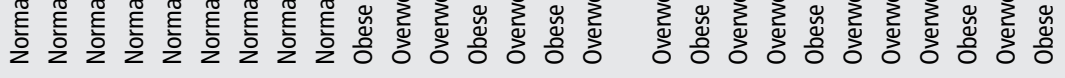

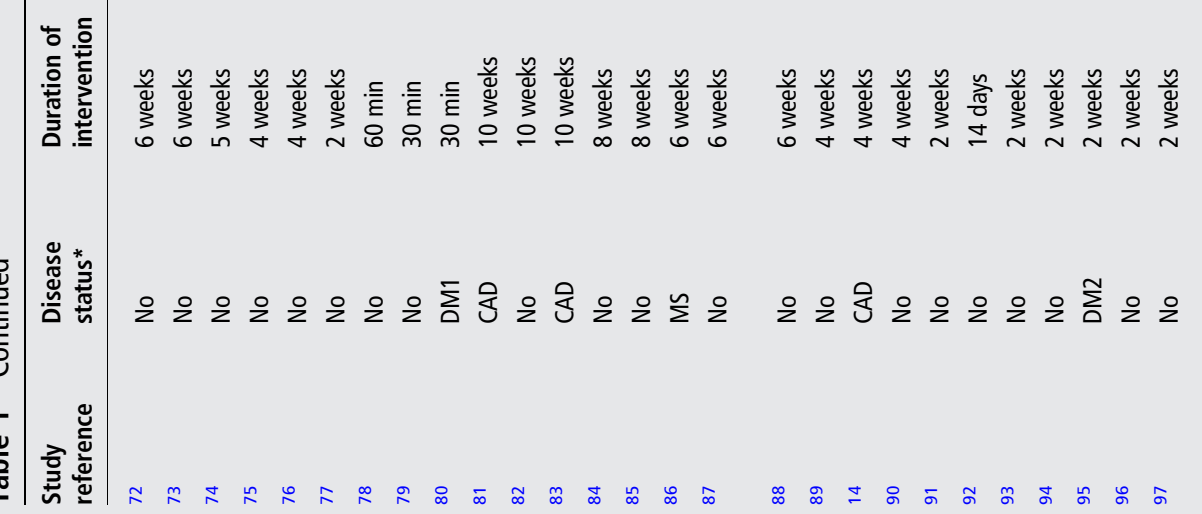

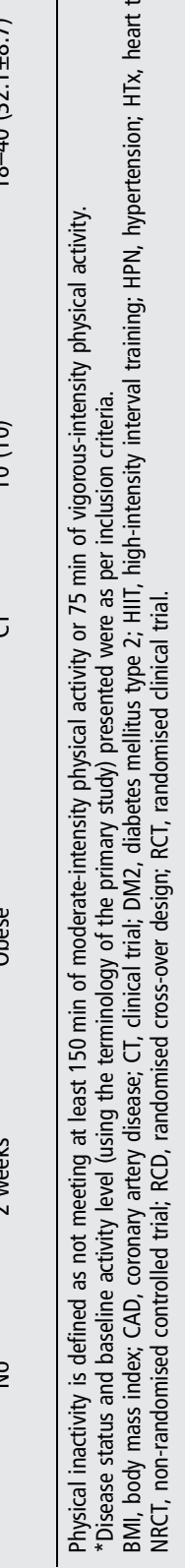


A

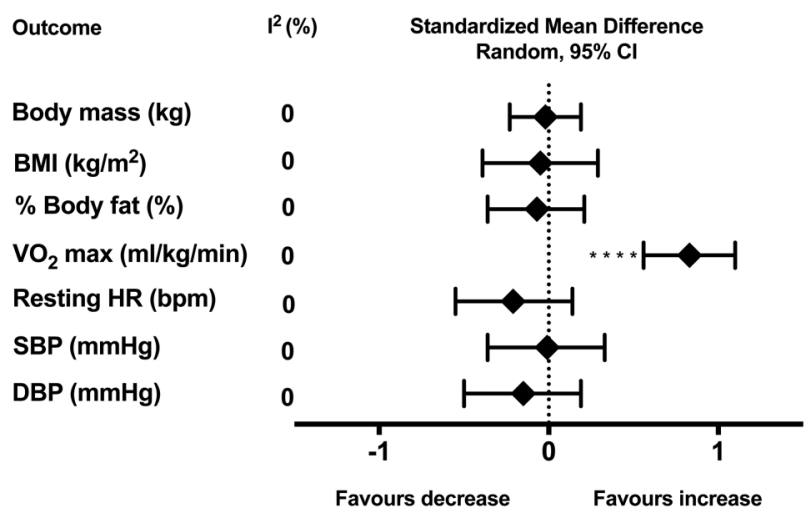

B

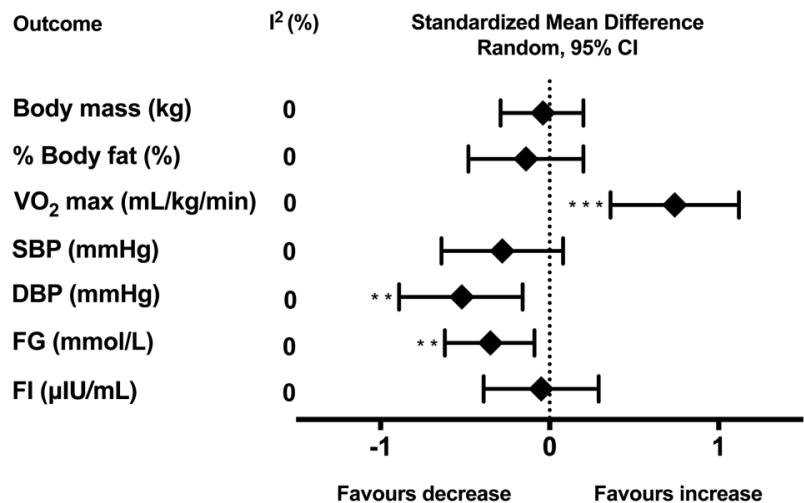

Figure 2 Summary estimates of the effect of ST-HIIT on cardiometabolic health variables in (A) normal weight and (B) overweight/obese populations. BMI, body mass index; DBP, diastolic blood pressure; FG, fasting glucose; Fl, fasting insulin; HR, heart rate; $\mathrm{I}^{2}, \mathrm{I}$-squared statistic for heterogeneity; SBP, systolic blood pressure; ST-HIIT, short-term high-intensity interval training; $\mathrm{VO}_{2}$ max, maximal oxygen uptake. ${ }^{* *} \mathrm{p}<0.01,{ }^{* * *} \mathrm{p}<0.001,{ }^{* * *} \mathrm{p}<0.00001$.

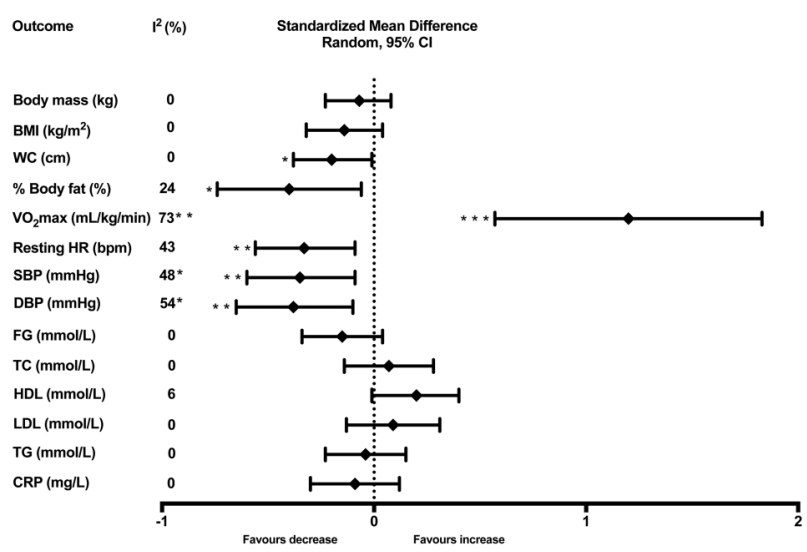

Figure 3 Summary estimates of the effect of LT-HIIT on cardiometabolic health variables in overweight/obese populations. BMI, body mass index; CRP, C reactive protein; DBP, diastolic blood pressure; FG, fasting glucose; HDL, high-density lipoprotein cholesterol; $H R$, heart rate; $I^{2}$, I-squared statistic for heterogeneity; LDL, low-density lipoprotein cholesterol; LT-HIIT, long-term high-intensity interval training; SBP, systolic blood pressure; TC, total cholesterol; TG, triglycerides; $\mathrm{VO}_{2}$ max, maximal oxygen uptake; WC, waist circumference. ${ }^{*} p<0.05,{ }^{* *} p<0.01,{ }^{* * *} p<0.001$.
HIIT and body composition measures

ST-HIIT showed no effect on body mass (SMD -0.02 , 95\% CI -0.23 to $0.19 ; \mathrm{p}=0.87$ ), BMI (SMD $-0.0595 \% \mathrm{CI}-0.39$ to $0.29 ; \mathrm{p}=0.77$ ) and $\%$ body fat (SMD $-0.07,95 \% \mathrm{CI}-0.36$ to $0.21 ; \mathrm{p}=0.62$ ) in normal weight populations, with no significant heterogeneity across studies for body mass, BMI and \% body fat $\left(\mathrm{I}^{2}=0 \% ; \mathrm{p}=1.0\right.$ for all outcomes). Similarly, ST-HIIT showed no effect on body mass (SMD $-0.04,95 \%$ CI -0.29 to 0.20 ; $\mathrm{p}=0.72)$ and $\%$ body fat (SMD $-0.14,95 \%$ CI -0.48 to 0.20 ; $\mathrm{p}=0.42$ ) in overweight/obese populations, with no significant heterogeneity across studies $\left(I^{2}=0 \% ; p=1.0\right)$. The summary coding revealed no evidence for the effect of ST-HIIT on WC in normal weight populations and no evidence for the effect of ST-HIIT on BMI in overweight/obese populations. Conversely, summary coding showed that ST-HIIT reduced WC in overweight/obese populations.

There were insufficient studies to examine the effect of LT-HIIT on body composition in normal weight populations. LT-HIIT reduced WC (SMD $-0.20,95 \%$ CI -0.38 to -0.01 ; $\mathrm{p}<0.05$ ) and $\%$ body fat (SMD $-0.40,95 \%$ CI -0.74 to $-0.06 ; \mathrm{p}<0.05)$ by a small effect in overweight/obese populations, with no significant heterogeneity across studies $\left(\mathrm{I}^{2}=0 \%\right.$; $\mathrm{p}=0.74$ for $\mathrm{WC}, \mathrm{I}^{2}=24 \% ; \mathrm{p}=0.25$ for $\%$ body fat). However, LT-HIIT showed no effect on body mass (SMD $-0.07,95 \%$ CI -0.23 to $0.08 ; \mathrm{p}=0.37$ ) and BMI (SMD $-0.14,95 \% \mathrm{CI}-0.32$ to $0.04 ; p=0.12$ ) in overweight/obese populations, with no significant heterogeneity across studies $\left(\mathrm{I}^{2}=0 \% ; \mathrm{p}=0.95\right.$ for body mass, $\mathrm{I}^{2}=0 \% ; \mathrm{p}=0.62$ for BMI). Furthermore, summary coding revealed that the effect of LT-HIIT on WHR was inconsistent in overweight/obese populations.

\section{HIIT and cardiorespiratory measures}

ST-HIIT increased $\mathrm{VO}_{2}$ max (SMD 0.83, 95\% CI 0.56 to 1.10; $\mathrm{p}<0.00001)$ by a large effect in normal weight populations and increased $\mathrm{VO}_{2} \max$ (SMD 0.74, 95\% CI 0.36 to 1.12; $\mathrm{p}<0.001$ ) by a medium effect in overweight/obese populations, with no significant heterogeneity across studies $\left(\mathrm{I}^{2}=0 \%\right.$; $\mathrm{p}=0.52$ for normal weight; $\mathrm{I}^{2}=0 \% ; \mathrm{p}=0.62$ for overweight/ obese). While the summary coding revealed that LT-HIIT increased $\mathrm{VO}_{2}$ max in normal weight populations. LT-HIIT improved $\mathrm{VO}_{2}$ max (SMD 1.20, 95\% CI 0.57 to 1.83; $\mathrm{p}<0.001)$ by a large effect in overweight/obese populations, with significant heterogeneity across studies $\left(\mathrm{I}^{2}=73 \% ; \mathrm{p}<0.01\right)$.

ST-HIIT showed no effect on resting HR (SMD $-0.21,95 \%$ CI -0.55 to $0.14 ; p=0.24$ ) in normal weight populations, with no significant heterogeneity across studies $\left(\mathrm{I}^{2}=0 \% ; \mathrm{p}=0.81\right)$. There was no evidence in the summary coding for the effect of ST-HIIT on resting HR in overweight/obese populations and no evidence for the effect of LT-HIIT on resting HR in normal weight populations. In contrast, LT-HIIT decreased resting HR (SMD $-0.33,95 \%$ CI -0.56 to $-0.09 ; \mathrm{p}<0.01$ ) by a small effect in overweight/obese populations, with no significant heterogeneity across studies $\left(\mathrm{I}^{2}=43 \% ; \mathrm{p}=0.07\right)$.

ST-HIIT showed no effect on systolic BP (SBP; SMD -0.01 , 95\% CI -0.36 to $0.33 ; \mathrm{p}=0.95$ ) and diastolic BP (DBP; SMD $-0.15,95 \% \mathrm{CI}-0.50$ to 0.19 ; $\mathrm{p}=0.39$ ) in normal weight $\mathrm{popu}-$ lations, with no significant heterogeneity across studies $\left(\mathrm{I}^{2}=0 \%\right.$; $\mathrm{p}=0.91$ for SBP; $\mathrm{I}^{2}=0 \% ; \mathrm{p}=0.98$ for DBP). While ST-HIIT showed no effect on SBP (SMD $-0.28,95 \%$ CI -0.64 to 0.08 ; $\mathrm{p}=0.12$ ) and decreased DBP (SMD $-0.52,95 \%$ CI -0.89 to $-0.16 ; \mathrm{p}<0.01$ ) by a medium effect in overweight/obese populations, with no significant heterogeneity across studies $\left(\mathrm{I}^{2}=0 \%\right.$; $\mathrm{p}=0.98$ for $\mathrm{SBP} ; \mathrm{I}^{2}=0 \% ; \mathrm{p}=0.79$ for $\left.\mathrm{DBP}\right)$. The summary 
Table 2 Summary coding of studies examining the effect of HIIT on cardiometabolic health variables

\begin{tabular}{|c|c|c|c|c|c|}
\hline \multirow[b]{2}{*}{ HIIT duration ion } & \multirow[b]{2}{*}{ Marker } & \multicolumn{2}{|c|}{ Normal weight population } & \multicolumn{2}{|c|}{ Overweight/obese population } \\
\hline & & $\mathrm{n} / \mathrm{N}(\%)^{*}+\ddagger$ & Effect $(0 /-/+/ ?) \S$ & $\mathrm{n} / \mathrm{N}(\%)^{*}+\ddagger$ & Effect $(0 /-/+/ ?) \S$ \\
\hline \multirow[t]{19}{*}{ ST-HIIT } & BM & NR & NA & NR & NA \\
\hline & BMI & NR & NA & $1 / 4(25 \%)$ & No $(0)$ \\
\hline & WC & $0 / 2(0 \%)$ & No $(0)$ & $2 / 3(67 \%)$ & Positive (+) \\
\hline & WHR & $0 / 1(0 \%)$ & NA & $0 / 0(0 \%)$ & NA \\
\hline & $\% \mathrm{BF}$ & NR & NA & NR & NA \\
\hline & RHR & NR & NA & $1 / 3(33 \%)$ & No $(0)$ \\
\hline & $\mathrm{VO}_{2} \max$ & NR & NA & NR & NA \\
\hline & SBP & NR & NA & NR & NA \\
\hline & DBP & NR & NA & NR & NA \\
\hline & FG & $2 / 4(50 \%)$ & Inconsistent (?) & NR & NA \\
\hline & $\mathrm{FI}$ & $0 / 2(0 \%)$ & No $(0)$ & NR & NA \\
\hline & $\mathrm{HbA1C}$ & $0 / 0(0 \%)$ & NA & $1 / 1(100 \%)$ & NA \\
\hline & $\mathrm{TC}$ & $1 / 2(50 \%)$ & Inconsistent (?) & $1 / 3(33 \%)$ & No $(0)$ \\
\hline & HDL & $1 / 3(33 \%)$ & No $(0)$ & $0 / 4(0 \%)$ & No $(00)$ \\
\hline & LDL & $1 / 2(50 \%)$ & Inconsistent (?) & $1 / 3(33 \%)$ & No $(0)$ \\
\hline & TG & $0 / 2(0 \%)$ & No $(0)$ & $0 / 5(0 \%)$ & No $(00)$ \\
\hline & CRP & $0 / 0(0 \%)$ & NA & $0 / 1(0 \%)$ & NA \\
\hline & IL-6 & $1 / 2(50 \%)$ & Inconsistent (?) & $0 / 1(0 \%)$ & NA \\
\hline & TNF- $\alpha$ & $0 / 1(0 \%)$ & NA & $0 / 1(0 \%)$ & NA \\
\hline \multirow[t]{19}{*}{ LT-HIIT } & $\mathrm{BM}$ & $0 / 1(0 \%)$ & NA & NR & NA \\
\hline & BMI & $0 / 1(0 \%)$ & NA & NR & NA \\
\hline & WC & $0 / 0(0 \%)$ & NA & NR & NA \\
\hline & WHR & $0 / 0(0 \%)$ & NA & $2 / 4(50 \%)$ & Inconsistent (?) \\
\hline & $\% B F$ & $0 / 0(0 \%)$ & NA & NR & NA \\
\hline & RHR & $0 / 2(0 \%)$ & No $(0)$ & NR & NA \\
\hline & $\mathrm{VO}_{2} \max$ & $4 / 4(100 \%)$ & Positive $(++)$ & NR & NA \\
\hline & SBP & $1 / 2(50 \%)$ & Inconsistent (?) & NR & NA \\
\hline & DBP & $1 / 2(50 \%)$ & Inconsistent (?) & NR & NA \\
\hline & FG & $0 / 2(0 \%)$ & No $(0)$ & $\mathrm{NR}$ & NA \\
\hline & $\mathrm{FI}$ & $1 / 1(100 \%)$ & NA & $0 / 3(0 \%)$ & No $(0)$ \\
\hline & $\mathrm{HbA1C}$ & $0 / 0(0 \%)$ & NA & $1 / 5(20 \%)$ & No $(00)$ \\
\hline & TC & $0 / 2(0 \%)$ & No $(0)$ & NR & NA \\
\hline & HDL & $0 / 2(0 \%)$ & No (0) & NR & NA \\
\hline & LDL & $0 / 1(0 \%)$ & NA & NR & NA \\
\hline & TG & $0 / 2(0 \%)$ & No $(0)$ & NR & NA \\
\hline & CRP & $0 / 0(0 \%)$ & NA & $\mathrm{NR}$ & NA \\
\hline & IL-6 & $0 / 0(0 \%)$ & NA & $0 / 2(0 \%)$ & No $(0)$ \\
\hline & TNF- $\alpha$ & $0 / 0(0 \%)$ & NA & $1 / 1(100 \%)$ & NA \\
\hline
\end{tabular}

${ }^{*} \mathrm{n}=$ number of studies reporting difference in the expected direction.

$\mathrm{t}=$ number of identified studies of interest.

$\ddagger(\%)=$ percentage of studies reporting differences in the expected direction.

§Summary effect. No effect (0): 0-33\% of studies reported significant differences; inconsistent (?): $34-59 \%$ of studies reported significant differences; positive (+) or negative (-) effect: $60-100 \%$ of studies demonstrated significant differences; $\geq 4$ studies: positive (++), negative (--), no effect (00), inconsistent findings (??).

$\% \mathrm{BF}$, body fat percentage; BM, body mass; BMI, body mass index; CRP, C reactive protein; DBP, diastolic blood pressure; FG, fasting glucose; FI, fasting insulin; HbA1C, glycosylated haemoglobin; HDL, high-density lipoprotein cholesterol; HIIT, high-intensity interval training; IL-6, interleukin 6; LDL, low-density lipoprotein cholesterol; NA, not applicable; NR, no reported summary coding (a meta-analysis was performed); RHR, resting heart rate; SBP, systolic blood pressure; TC, total cholesterol; TG, triglycerides; TNF- $\alpha$, tumour necrosis factor- $\alpha$; $\mathrm{VO}_{2}$ max, maximal oxygen uptake; WC, waist circumference; WHR, waist-to-hip ratio.

coding revealed that the effect of LT-HIIT on SBP and DBP was inconsistent in normal weight populations. LT-HIIT decreased SBP (SMD $-0.35,95 \%$ CI -0.60 to $-0.09 ; \mathrm{p}<0.01$ ) and DBP (SMD $-0.38,95 \%$ CI -0.65 to $-0.10 ; \mathrm{p}<0.01$ ) by a small effect in overweight/obese populations, with significant heterogeneity across studies $\left(\mathrm{I}^{2}=48 \%, \mathrm{p}<0.05\right.$ for $\mathrm{SBP} ; \mathrm{I}^{2}=54 \%$, $\mathrm{p}<0.05$ for DBP).

\section{HIIT and glucose metabolism measures}

The summary coding revealed that the evidence for the effect of ST-HIIT on fasting glucose was inconsistent and no evidence for the effect of ST-HIIT on fasting insulin in normal weight populations. Alternatively, ST-HIIT reduced fasting glucose (SMD $-0.35,95 \%$ CI -0.62 to $-0.09 ; \mathrm{p}<0.01$ ) by a small effect and showed no effect on fasting insulin (SMD -0.05, $95 \%$ CI -0.39 to $0.29 ; \mathrm{p}=0.76$ ) in overweight/obese populations, with no significant heterogeneity across studies $\left(\mathrm{I}^{2}=0 \%\right.$, $\mathrm{p}=0.51$ for fasting glucose; $\mathrm{I}^{2}=0 \%, \mathrm{p}=0.95$ for fasting insulin). The summary coding revealed no evidence for the effect of LT-HIIT on fasting glucose in normal weight populations. Similarly, LT-HIIT demonstrated no effect on fasting glucose (SMD $-0.15,95 \% \mathrm{CI}-0.34$ to $0.04 ; \mathrm{p}=0.11$ ) in overweight/ obese populations, with no significant heterogeneity across studies $\left(\mathrm{I}^{2}=0 \% ; \mathrm{p}=1.0\right)$. There was no evidence in the summary 
coding for the effect of LT-HIIT on fasting insulin and HbA1c in overweight/obese populations.

\section{HIIT and blood lipid measures}

The summary coding revealed that the evidence for the effect of ST-HIIT on total cholesterol and LDL cholesterol was inconsistent and no evidence for the effect of ST-HIIT on HDL cholesterol and triglycerides in normal weight populations. There was no evidence in the summary coding for the effect of ST-HIIT on total cholesterol, HDL cholesterol, LDL cholesterol and triglycerides in overweight/obese populations. The summary coding revealed no evidence for the effect of LT-HIIT on total cholesterol, HDL cholesterol and triglycerides in normal weight populations. LT-HIIT demonstrated no effect on total cholesterol (SMD 0.07, 95\% CI -0.14 to $0.28 ; \mathrm{p}=0.51$ ), HDL cholesterol (SMD 0.20, 95\% CI -0.01 to $0.40 ; \mathrm{p}=0.06$ ), LDL cholesterol (SMD 0.09, 95\% CI -0.13 to $0.31 ; \mathrm{p}=0.42$ ) and triglycerides (SMD $-0.04,95 \% \mathrm{CI}-0.23$ to $0.15 ; \mathrm{p}=0.67$ ) in overweight/obese populations, with no significant heterogeneity across studies $\left(\mathrm{I}^{2}=0 \%, \mathrm{p}=0.73\right.$ for total cholesterol; $\mathrm{I}^{2}=6 \%$, $\mathrm{p}=0.38$ for HDL; $\mathrm{I}^{2}=0 \%, \mathrm{p}=0.93$ for $\mathrm{LDL} ; \mathrm{I}^{2}=0 \%, \mathrm{p}=0.91$ for triglycerides).

\section{HIIT and inflammation measures}

The summary coding revealed that the evidence for the effect of ST-HIIT on IL-6 was inconsistent in normal weight populations. There was no evidence in the summary coding for the effect of LT-HIIT on IL-6 in overweight/obese populations. LT-HIIT showed no effect on CRP (SMD $-0.09,95 \%$ CI -0.30 to 0.12; $\mathrm{p}=0.39$ ) in overweight/obese populations, with no significant heterogeneity across studies $\left(\mathrm{I}^{2}=0 \% ; \mathrm{p}=0.94\right)$.

\section{Meta-regression}

Table 3 shows the $\beta$-coefficients and CIs for the meta-regression analyses. Intervention duration, total HIIT time used (min), BMI and baseline level of the outcome variable did not predict the improvements observed in SBP and DBP. Intervention duration $\left(\beta(95 \% \mathrm{CI})=0.77(0.35,1.18) ; \mathrm{R}^{2}=0.94\right)$ and BMI $(\beta$ $\left.(95 \% \mathrm{CI})=0.84(0.29,1.38) ; \mathrm{R}^{2}=0.73\right)$ predicted changes in $\mathrm{VO}_{2}$ max. Greater increases in $\mathrm{VO}_{2}$ max were associated with longer intervention duration and higher BMI.

\section{DISCUSSION}

Results suggest that HIIT is an effective intervention to improve cardiometabolic health in overweight/obese populations. Specifically, ST-HIIT beneficially influenced $\mathrm{WC}, \mathrm{VO}_{2} \max$, fasting glucose and DBP, whereas LT-HIIT was found to beneficially influence WC, \% body fat, $\mathrm{VO}_{2}$ max, resting $\mathrm{HR}$, SBP and DBP in overweight/obese populations.

Meta-analysis of ST-HIIT revealed no significant effect on body composition in normal weight populations, whereas too few studies are currently available examining the effect of
LT-HIIT in normal weight populations. ST-HIIT reduced WC in overweight/obese populations and LT-HIIT significantly improved WC and \% body fat in overweight/obese populations. The average change in WC was $2.13 \mathrm{~cm}$ for ST-HIIT and $2.23 \mathrm{~cm}$ for LT-HIIT, both above the cut-off value of $>2 \mathrm{~cm}$ WC decrease which is suggested to confer improvements in metabolic syndrome risk factors. ${ }^{98}$ These findings suggest that HIIT is an effective stimulus for reducing body fat levels (even in the absence of weight loss) for those individuals with large fat mass. Possible mechanisms underlying HIIT-induced fat loss include generation of catecholamines that increased fat oxidation and fat release from visceral fat stores, decreased postexercise appetite and increased excess postexercise oxygen consumption resulting in an elevated fat loss state. ${ }^{99} 100$ A catecholamine response has been shown to be significantly elevated after HIIT. ${ }^{101} 102$ Since $\beta_{3}$-adrenergic receptors are located mainly in the adipose tissue ${ }^{103}$ and $\beta$-adrenergic receptor sensitivity in adipose tissue is increased following exercise, ${ }^{104}$ these factors might explain why HIT is effective in reducing body fat in overweight/obese individuals. One intriguing finding is the absence of weight loss despite observed decrease in body fat, this is likely to be a consequence of gain in muscle mass. HIIT is known to recruit more fast type II muscle fibres leading to greater muscle hypertrophy and muscle mass. ${ }^{105} 106$ This adaptation is likely to induce health benefits as increase in muscle mass improves insulin sensitivity. ${ }^{107}$ As an example, elevated muscle mass was found positively associated with reduced incidence of insulin resistance and metabolic syndrome. ${ }^{108} 109$ Thus, if HIIT can be successfully implemented in settings outside of clinical trials, it may offer an additional strategy to assist with adipose reduction in overweight/obese populations. However, more studies are required to determine whether HIIT could be a successful population-based strategy for producing health adaptations.

Results from meta-analysis consistently revealed that ST-HIIT significantly improved $\mathrm{VO}_{2}$ max by medium effects to large effects in normal weight (SMD $0.83,95 \%$ CI 0.56 to 1.10 ; $\mathrm{p}<0.00001$ ) and overweight/obese (SMD 0.74, 95\% CI 0.36 to $1.12 ; \mathrm{p}<0.001)$ populations, with an aggregate improvement of 3.80 and $4.43 \mathrm{~mL} / \mathrm{kg} / \mathrm{min}$, respectively. The summary coding revealed that LT-HIIT increased $\mathrm{VO}_{2}$ max in normal weight populations, whereas the meta-analysis showed that LT-HIIT significantly improved $\mathrm{VO}_{2}$ max by large effects in overweight obese (SMD 1.20, 95\% CI 0.57 to 1.83 ; $\mathrm{p}<0.001$ ) populations with an aggregate improvement of $6.04 \mathrm{~mL} / \mathrm{kg} / \mathrm{min}$. These findings are similar to previous meta-analyses which have demonstrated that HIIT improves aerobic fitness by moderate effects to large effects (Hedges' g=0.63, 95\% CI 0.39 to 0.87 ; SMD $0.86,95 \% \mathrm{CI} 0.72$ to 0.99 ) in healthy sedentary and recreationally active young adults ${ }^{12} 1921110$ and in adults with cardiometabolic disorders. ${ }^{18}{ }^{23}$ Notably, ST-HIIT and LT-HIT improve $\mathrm{VO}_{2}$ max in normal weight and overweight/obese populations

Table 3 Meta-regression coefficients of the effect of significant moderators on selected outcomes

\begin{tabular}{|c|c|c|c|c|}
\hline \multirow[b]{2}{*}{ Marker } & \multicolumn{4}{|l|}{$\boldsymbol{\beta}(95 \% \mathrm{Cl})$} \\
\hline & Intervention duration & Total HIIT time used (min) & BMI & Baseline level \\
\hline $\mathrm{VO}_{2} \max$ & $0.7677(0.3510 \text { to } 1.1844)^{*}$ & $0.0002(-0.0017$ to 0.0021$)$ & $0.8366(0.2948 \text { to } 1.3785)^{*}$ & $-0.3928(-1.0735$ to 0.2879$)$ \\
\hline SBP & $0.0192(-0.0575$ to 0.0960$)$ & $0.0003(-0.0004$ to 0.0010$)$ & $-0.1169(-0.3611$ to 0.1274$)$ & $-0.0210(-0.0432$ to 0.0011$)$ \\
\hline DBP & $0.0191(-0.0620$ to 0.1001$)$ & $0.0003(-0.0004$ to 0.0010$)$ & -0.0809 ( -0.3434 to 0.1816$)$ & $0.0053(-0.0177$ to 0.0283$)$ \\
\hline
\end{tabular}


with larger gains observed for longer training periods. This has implications for the use of HIIT as part of lifestyle modification strategies and is consistent with training responses to stimuli. The ability of ST-HIIT and LT-HIIT has clinical applications in individuals that need to improve their aerobic fitness as HIIT is able to increase $\mathrm{VO}_{2}$ max rapidly via increasing mitochondrial density, resulting in the generation of more ATP for working muscles, thereby producing greater force generation for a longer duration. ${ }^{111}$ HIIT is also able to increase stroke volume induced by increased cardiac contractility ${ }^{64}$ and increase skeletal muscle diffusive capacity, ${ }^{112}$ thus improving aerobic capacity.

This review also found LT-HIIT to significantly decrease resting HR in overweight/obese populations, but not in normal weight populations subjected to LT-HIIT and in normal weight/ overweight/obese populations subjected to ST-HIIT. The decrease in resting HR following LT-HITT may be explained by increased stroke volume ${ }^{64}$ and improved cardiac autonomic function via increased baroreflex-mediated modulation of the sinoatrial node. ${ }^{113}$ Taken together, these improvements in cardiorespiratory fitness $\left(\mathrm{VO}_{2} \max \right)$ and $\mathrm{HR}$ response provided by HIIT are important since both are independent predictors of allcause and CVD mortality. ${ }^{114-116}$

BP is another commonly assessed measure related to cardiovascular health. ST-HIIT showed no significant effect on SBP and DBP in normal weight populations. While ST-HIIT showed no significant effect on SBP in normal weight and overweight/ obese populations, ST-HIIT significantly improved DBP in overweight/obese populations with an average reduction of $4.74 \mathrm{~mm} \mathrm{Hg}$. This lack of change observed in SBP following ST-HIIT is perhaps due to the fact that most of the participants in this group were middle aged to older aged (40.9-62.9 years old), and it is well known that SBP increases progressively with age. ${ }^{117}$ It is possible that longer HIIT intervention periods are required to produce a significant effect in SBP in this population. This is supported by the observation that LT-HIIT significantly decreased SBP and DBP in overweight/obese populations. The average reduction is $4.57 \mathrm{~mm} \mathrm{Hg}$ for SBP and $2.94 \mathrm{~mm} \mathrm{Hg}$ for DBP, above $4 \mathrm{~mm} \mathrm{Hg}$ SBP reduction which is expected to decrease CVD mortality by $5-20 \% .{ }^{118}$ The findings of the current study demonstrate the beneficial impact of HIIT in overweight/obese populations. The mechanisms responsible for the BP lowering effect of HIIT may result from intensity-dependent increases to blood flow velocity, resulting in increased levels of endothelial nitric oxide (NO). ${ }^{119}{ }^{120}$ Increases in endothelial NO availability and bioactivity improve NO-dependent vasodilation in the vasculature, resulting in improved peripheral compliance and decreased $\mathrm{BP}^{121}$

ST-HIIT and LT-HIIT showed no significant effect on glucose/ insulin response in normal weight populations. No changes in fasting glucose/insulin were observed in overweight/obese populations subjected to LT-HIIT, but a decrease in fasting glucose was observed in overweight/obese populations subjected to ST-HIIT. The reason for improvement in glucose response in ST-HIIT is not fully known, but activation of AMP-activated kinase (AMPK) has been shown to increase glucose uptake in skeletal muscle via increased translocation of GLUT4. ${ }^{122} 123$ Interestingly, no significant effect was observed in glucose/ insulin response following LT-HIIT in overweight/obese populations. One explanation is that all the LT-HIIT studies that examined glucose metabolism were conducted in participants with a pre-existing medical condition (coronary artery disease, metabolic syndrome and hypertension) that is known to independently influence glucose metabolism, thus possibly obscuring the effect of HIIT on glucose metabolism.
There was no evidence to suggest that ST-HIIT and LT-HIIT influence blood lipids in normal weight and overweight/obese populations. Although the exact cause is unknown, a possible explanation is that HIIT decreases fatty acid release in the circulation due to decreased blood flow in adipose tissue mediated by $\alpha 2$-adrenergic receptors during high plasma catecholamine concentrations. ${ }^{124}$ This is an area that requires further examination.

The role of inflammation in diabetes and CVD risk is increasingly acknowledged. ${ }^{125}$ Inflammation contributes to the development of CVD by narrowing arteries ${ }^{126}$ and diabetes by promoting insulin resistance. ${ }^{127}$ ST-HIIT demonstrated no effect on IL-6 in normal weight populations, whereas LT-HIIT demonstrated no effect on CRP and IL-6 in overweight/obese populations. One LT-HIIT study reported improvements in TNF- $\alpha$ in obese, middle-aged to older-aged adults. At present, the effect of HIIT on inflammation is not clear. The small number of studies combined with the varied populations made synthesis of studies difficult. Furthermore, evidence suggests that the duration of individual bouts of exercise is the single most important factor that determines the magnitude of the systemic IL-6 response. ${ }^{128}$ The short bouts of exercise used in some of the studies included in this review may not be long enough to elicit a pronounced IL- 6 response despite the high intensity of HIIT. Thus, studies addressing these issues are encouraged to better understand the impact of HIIT on inflammatory markers.

This review demonstrates that HIIT performed $<12$ weeks and $\geq 12$ weeks can significantly improve $\mathrm{VO}_{2}$ max in normal weight and overweight/obese populations, $<12$ weeks of HIIT can significantly improve WC, fasting glucose and DBP in overweight/obese populations and at least 12 weeks of HIIT appears to promote significant reductions in WC, \% body fat, resting HR, SBP and DBP in overweight/obese populations. However, despite the results observed for ST-HIIT and LT-HIIT in overweight/obese populations, there were too few studies of LT-HIIT in normal weight populations. The number of health-related benefits elicited by HIIT in overweight/obese populations is possibly related to the changes in fat mass following HIIT. Another explanation is that increase in adipose tissue induces metabolic dysregulation increasing responsiveness to HIIT. However, although improvements in cardiorespiratory fitness and body composition were observed, there were no evidence to suggest that lipid metabolism and inflammatory markers are influenced by ST-HIIT or LT-HIIT, possibly due to the different metabolic consequences of the different HIIT protocols causing different metabolic adaptations. The challenge therefore for future research is to identify the optimal length, work-to-rest ratio of HIIT that would provide maximum health benefit.

There are some limitations to this meta-analysis. The effect of sprint interval training (HIIT above $100 \% \mathrm{VO}_{2}$ max) separate to HIIT was not examined and is a potential area for future reviews. Most studies included are of low (16/65) to fair (46/65) quality and used relatively small sample sizes. The substantial heterogeneity found in several meta-analysed health markers (WC, $\mathrm{VO}_{2}$ max, HR, SBP and DBP) suggests differences in population cohorts and study design as possible sources. This issue was addressed by stratifying the results by study duration and BMI, and by performing a meta-regression. Additional studies conducted in larger and more diverse samples are required to address these limitations of primary studies.

\section{CONCLUSION}

Findings of this review indicate that HIIT may constitute an effective training protocol for improving $\mathrm{VO}_{2}$ max and several 
cardiometabolic risk factors such as WC, \% body fat, resting HR, SBP, DBP and fasting glucose in overweight/obese populations. Taken as a whole, in overweight/obese populations, performing HIIT results in significant, positive, physiological adaptations that improve cardiometabolic health and may reduce the development and progression of disease-related risk factors that are associated with overweight/obesity and low aerobic fitness. However, whether these metabolic adaptations following LT-HIIT extend to normal weight populations still needs further examination.

As HIIT activity regime requires minimal time commitment, HIT may serve as a time-efficient substitute or as a compliment to commonly recommended MICT in improving cardiometabolic health. Clinicians are encouraged (after an appropriate pre-exercise screening and under supervised conditions) to use HIIT performed at least three times a week for 12 weeks as part of their exercise programme to enhance cardiorespiratory fitness and to reduce body fat in overweight/ obese populations.

\section{What are the findings?}

- At least 12 weeks of high-intensity interval training (HIIT) improves cardiometabolic risk factors such as waist circumference, \% body fat, resting heart rate, systolic blood pressure and diastolic blood pressure in overweight/obese populations.

- Improvements in aerobic capacity are larger with longer training periods.

- The effect of HIIT on inflammation is not clear due to the limited number of studies available.

\section{How might it impact on clinical practice in the future?}

- High-intensity interval training (HIIT) performed at least 3 times a week for 12 weeks results in significant, positive, physiological adaptations that improve cardiometabolic health in overweight/obese populations.

- HIIT may reduce the development and progression of disease-related risk factors that are associated with overweight/obesity and low aerobic fitness.

- HIIT may be especially attractive to overweight/obese populations interested in improving cardiometabolic health but with limited time available.

Contributors All authors have made substantial contributions to the conception and design of the study. RBB executed the search strategy and screened the initial results of the literature searches. RBB and PST assessed studies for inclusion, appraised and extracted data from the included studies. RBB drafted the manuscript. All authors contributed to the critical revision of the manuscript and approved the final version.

Funding RBB is supported by the Strategic Research Scholarship grant from Central Queensland University. This manuscript is in part supported by CQUniversity Health CRN. MJD is supported by a Future Leader Fellowship (ID 100029) from the National Heart Foundation of Australia.

Competing interests None declared.

Provenance and peer review Not commissioned; externally peer reviewed.

\section{REFERENCES}

1 World Health Organization. WHO Global Recommendations on Physical Activity for Health. Geneva: World Health Organization, 2010.

2 American College of Sports Medicine. ACSM's guidelines for exercise testing and prescription. 8th edn. New York: Williams \& Wilkins, 2009.

3 Norton K, Norton L, Sadgrove D. Position statement on physical activity and exercise intensity terminology. J Sci Med Sport 2010;13:496-502.

4 Hallal PC, Andersen LB, Bull FC, et al. Global physical activity levels: surveillance progress, pitfalls, and prospects. Lancet 2012;380:247-57.

5 Godin G, Desharnais R, Valois $P$, et al. Differences in perceived barriers to exercise between high and low intenders: observations among different populations. Am J Health Promot 1994:8:279-85.

6 Reichert FF, Barros AJD, Domingues MR, et al. The role of perceived personal barriers to engagement in leisure-time physical activity. Am J Public Health 2007;97:515-19.

7 Babraj JA, Vollaard NBJ, Keast C, et al. Extremely short duration high intensity interval training substantially improves insulin action in young healthy males. BMC Endocr Disord 2009;9:1-8.

8 Burgomaster KA, Cermak NM, Phillips SM, et al. Divergent response of metabolite transport proteins in human skeletal muscle after sprint interval training and detraining. Am J Physiol Regul Integr Comp Physiol 2007;292 R1970-6

9 Burgomaster KA, Howarth KR, Phillips SM, et al. Similar metabolic adaptations during exercise after low volume sprint interval and traditional endurance training in humans. J Physiol (Lond) 2008;586:151-60.

10 Ciolac EG. High-intensity interval training and hypertension: maximizing the benefits of exercise? Am J Cardiovasc Dis 2012;2:102-10.

11 Gibala MJ, Little JP, Macdonald MJ, et al. Physiological adaptations to low-volume, high-intensity interval training in health and disease. J Physiol (Lond) 2012;590:1077-84.

12 Sloth $\mathrm{M}$, Sloth $\mathrm{D}$, Overgaard $\mathrm{K}$, et al. Effects of sprint interval training on $\mathrm{VO}_{2}$ max and aerobic exercise performance: a systematic review and meta-analysis. Scand J Med Sci Sports 2013;23:E341-52.

13 Trapp EG, Chisholm DJ, Freund J, et al. The effects of high-intensity intermittent exercise training on fat loss and fasting insulin levels of young women. Int J Obes (Lond) 2008;32:684-91.

14 Moholdt TT, Amundsen BH, Rustad LA, et al. Aerobic interval training versus continuous moderate exercise after coronary artery bypass surgery: a randomized study of cardiovascular effects and quality of life. Am Heart $J$ 2009;158:1031-7

15 Wisløff U, Støylen A, Loennechen JP, et al. Superior cardiovascular effect of aerobic interval training versus moderate continuous training in heart failure patients: a randomized study. Circulation 2007:115:3086-94.

16 Tjonna $A E$, Lee SJ, Rognmo 0, et al. Aerobic interval training versus continuous moderate exercise as a treatment for the metabolic syndrome: a pilot study. Circulation 2008;118:346-54

17 Ciolac EG, Bocchi EA, Bortolotto LA, et al. Effects of high-intensity aerobic interval training vs. moderate exercise on hemodynamic, metabolic and neuro-humoral abnormalities of young normotensive women at high familial risk for hypertension. Hypertens Res 2010;33:836-43.

18 Weston KS, Wisløff U, Coombes JS. High-intensity interval training in patients with lifestyle-induced cardiometabolic disease: a systematic review and meta-analysis. Br J Sports Med 2014;48:1227-34.

19 Weston M, Taylor KL, Batterham AM, et al. Effects of low-volume high-intensity interval training (HIT) on fitness in adults: a meta-analysis of controlled and non-controlled trials. Sports Med 2014;44:1005-17.

20 Kessler HS, Sisson SB, Short KR. The potential for high-intensity interval training to reduce cardiometabolic disease risk. Sports Med 2012;42:489-509.

21 Bacon AP, Carter RE, Ogle EA, et al. $\mathrm{VO}_{2}$ max trainability and high intensity interval training in humans: a meta-analysis. PLOS ONE 2013;8:E73182.

22 Ramos JS, Dalleck LC, Tjonna AE, et al. The impact of high-intensity interval training versus moderate-intensity continuous training on vascular function: a systematic review and meta-analysis. Sports Med 2015;45:679-92.

23 Hwang $\mathrm{CL}$, Wu YT, Chou CH. Effect of aerobic interval training on exercise capacity and metabolic risk factors in people with cardiometabolic disorders: a meta-analysis. J Cardiopulm Rehabil Prev 2011;31:378-85.

24 Olsen MO. Assessment of cardiovascular risk - the impact and future of non-traditional cardiovascular risk markers. Eur Cardiol 2010;6:10-13.

$25 \mathrm{Kim} J \mathrm{~S}$, Lee $\mathrm{YH}, \mathrm{Kim} J \mathrm{C}$, et al. Effect of exercise training of different intensities on anti-inflammatory reaction in streptozotocin-induced diabetic rats. Biol Sport 2014;31:73-9.

26 Liberati A, Altman DG, Tetzlaff J, et al. The PRISMA statement for reporting systematic reviews and meta-analyses of studies that evaluate healthcare interventions: explanation and elaboration. BMJ (Clinical Research ed.) 2009;339: b2700.

27 Monninkhof EM, Elias SG, Vlems FA, et al. Physical activity and breast cancer: a systematic review. Epidemiology 2007;18:137-57. 
28 Ainsworth BE, Haskell WL, Whitt MC, et al. Compendium of physical activities: an update of activity codes and MET intensities. Med Sci Sports Exerc 2000;32: S498-504.

29 Colombo CM, Macedo RMD, Fernandes-Silva MM, et al. Short-term effects of moderate intensity physical activity in patients with metabolic syndrome. Einstein (São Paulo) 2013;11:324-30.

30 Kim EJ, Cho SW, Kang JY, et al. Effects of a 12-week lifestyle intervention on health outcome and serum adipokines in middle-aged Korean men with borderline high blood pressure. J Am Coll Nutr 2012;31:352-60.

31 Downs SH, Black N. The feasibility of creating a checklist for the assessment of the methodological quality both of randomised and non-randomised studies of health care interventions. J Epidemiol Commun Health 1998;52:377-84.

32 Newell SA, Bowman JA, Cockburn JD. Can compliance with nonpharmacologic treatments for cardiovascular disease be improved? Am J Prev Med 2000;18:253-61.

33 World Health Organization. Obesity: preventing and managing the global endemic. WHO Technical Report Series No. 894. Geneva: World Health Organization, 2000.

34 Duncan M, Spence J, Mummery WK. Perceived environment and physical activity: a meta-analysis of selected environmental characteristics. Int I Behav Nutr Phys Act 2005;2:11.

35 Heishman SJ, Kleykamp BA, Singleton EG. Meta-analysis of the acute effects of nicotine and smoking on human performance. Psychopharmacology (Berl) 2010;210:453-69.

36 Cohen J. Statistical power analysis for the behavioral sciences. 2nd edn. Hillsdale, NJ: Lawrence Erlbaum Associates, 1988.

37 Sallis JF, Prochaska JJ, Taylor WC. A review of correlates of physical activity of children and adolescents. Med Sci Sports Exerc 2000;32:963-75.

38 Ciolac EG, Bocchi EA, Greve JM, et al. Heart rate response to exercise and cardiorespiratory fitness of young women at high familial risk for hypertension: effects of interval vs continuous training. Eur J Cardiovasc Prev Rehabil 2011;18:824-30.

39 Tremblay A, Simoneau JA, Bouchard C. Impact of exercise intensity on body fatness and skeletal muscle metabolism. Metab Clin Exp 1994;43:814-18.

40 Chtara M, Chamari K, Chaouachi M, et al. Effects of intra-session concurrent endurance and strength training sequence on aerobic performance and capacity. Br J Sports Med 2005;39:555-60.

41 Nytrøen K, Annette Rustad L, Erikstad I, et al. Effect of high-intensity interval training on progression of cardiac allograft vasculopathy. J Heart Lung Transplant 2013:32:1073-80

42 Rustad LA, Nytrøen K, Amundsen BH, et al. One year of high-intensity interval training improves exercise capacity, but not left ventricular function in stable heart transplant recipients: a randomised controlled trial. Eur J Prev Cardiol 2014:21:181-91.

43 Mohr M, Nordsborg NB, Lindenskov A, et al. High-intensity intermittent swimming improves cardiovascular health status for women with mild hypertension. BioMed Res Int 2014;2014:728289.

44 Conraads VM, Pattyn N, De Maeyer C, et al. Aerobic interval training and continuous training equally improve aerobic exercise capacity in patients with coronary artery disease: the SAINTEX-CAD study. Int I Cardiol 2015:179:203-10.

45 Keating SE, Machan EA, O'Connor HT, et al. Continuous exercise but not high intensity interval training improves fat distribution in overweight adults. J Obes 2014;2014:12.

46 Madssen E, Arbo I, Graniien I, et al. Peak oxygen uptake after cardiac rehabilitation: a randomized controlled trial of a 12-month maintenance program versus usual care. PLOS ONE 2014;9:E107924.

47 Mitranun $\mathrm{W}$, Deerochanawong $\mathrm{C}$, Tanaka $\mathrm{H}$, et al. Continuous vs interval training on glycemic control and macro- and microvascular reactivity in type 2 diabetic patients. Scand J Med Sci Sports 2014;24:E69-76.

48 Astorino TA, Schubert MM, Palumbo E, et al. Effect of two doses of interval training on maximal fat oxidation in sedentary women. Med Sci Sports Exerc 2013;45:1878-86.

49 Heydari M, Boutcher YN, Boutcher SH. The effects of high-intensity intermittent exercise training on cardiovascular response to mental and physical challenge. Int J Psychophysiol 2013;87:141-6.

50 Heydari M, Boutcher YN, Boutcher SH. High-intensity intermittent exercise and cardiovascular and autonomic function. Clin Auton Res 2013;23:57-65.

51 Heydari M, Boutcher SH. Rating of perceived exertion after 12 weeks of high-intensity, intermittent sprinting. Percept Mot Skills 2013;116:340-51.

52 Terada T, Friesen A, Chahal BS, et al. Feasibility and preliminary efficacy of high intensity interval training in type 2 diabetes. Diabetes Res Clin $\mathrm{Pr}$ 2013:99:120-9.

53 Moholdt T, Aamot IL, Granoien I, et al. Aerobic interval training increases peak oxygen uptake more than usual care exercise training in myocardial infarction patients: a randomized controlled study. Clin Rehabil 2012;26:33-44.

54 Molmen-Hansen HE, Stolen T, Tjonna AE, et al. Aerobic interval training reduces blood pressure and improves myocardial function in hypertensive patients. Eur J Prev Cardiol 2012;19:151-60.
55 Stensvold D, Slordahl SA, Wisloff U. Effect of exercise training on inflammation status among people with metabolic syndrome. Metab Syndr Relat Disord 2012;10:267-72.

56 Sijie $T$, Hainai $Y$, Fengying $Y$, et al. High intensity interval exercise training in overweight young women. J Sports Med Phys Fitness 2012;52:255-62.

57 Stensvold D, Tjønna AE, Skaug EA, et al. Strength training versus aerobic interval training to modify risk factors of metabolic syndrome. J Appl Physiol 2010;108:804-10.

58 Schjerve IE, Tyldum GA, Tjønna AE, et al. Both aerobic endurance and strength training programmes improve cardiovascular health in obese adults. Clin Sci 2008;115:283-93.

59 Esfarjani F, Laursen PB. Manipulating high-intensity interval training: effects on $\mathrm{VO}_{2}$ max, the lactate threshold and $3000 \mathrm{~m}$ running performance in moderately trained males. J Sci Med Sport 2007;10:27-35.

60 Dupont G, Akakpo K, Berthoin S. The effect of in-season, high-intensity interval training in soccer players. J Strength Cond Res 2004;18:584-9.

61 Matsuo T, Saotome K, Seino S, et al. Effects of a low-volume aerobic-type interval exercise on $\mathrm{VO}_{2}$ max and cardiac mass. Med Sci Sports Exerc 2014;46:42-50.

62 Sandvei M, Jeppesen PB, Stoen L, et al. Sprint interval running increases insulin sensitivity in young healthy subjects. Arch Physiol Biochem 2012;118:139-47.

63 Musa DI, Adeniran SA, Dikko AU, et al. The effect of a high-intensity interval training program on high-density lipoprotein cholesterol in young men. J Strength Cond Res 2009;23:587-92.

64 Helgerud J, Hoydal $\mathrm{K}$, Wang $\mathrm{E}$, et al. Aerobic high-intensity intervals improve $\mathrm{VO}_{2}$ max more than moderate training. Med Sci Sports Exerc 2007;39:665-71.

65 Abderrahman $A B$, Zouhal $H$, Chamari $K$, et al. Effects of recovery mode (active vs. passive) on performance during a short high-intensity interval training program: a longitudinal study. Eur J Appl Physiol 2013;113:1373-83.

66 Macdougall JD, Hicks AL, Macdonald JR, et al. Muscle performance and enzymatic adaptations to sprint interval training. J App/ Physiol 1998;84:2138-42.

67 Cocks M, Shaw CS, Shepherd SO, et al. Sprint interval and endurance training are equally effective in increasing muscle microvascular density and eNOS content in sedentary males. J Physiol 2013;591:641-56.

68 Shepherd SO, Cocks M, Tipton KD, et al. Sprint interval and traditional endurance training increase net intramuscular triglyceride breakdown and expression of perilipin 2 and 5. J Physiol 2013;591:657-75

69 Walter AA, Smith $A E$, Kendall KL, et al. Six weeks of high-intensity interval training with and without beta-alanine supplementation for improving cardiovascular fitness in women. J Strength Cond Res 2010;24:1199-207.

70 Croft L, Bartlett JD, MacLaren DP, et al. High-intensity interval training attenuates the exercise-induced increase in plasma IL-6 in response to acute exercise. Appl Physiol Nutr Metab 2009;34:1098-107.

71 Gormley SE, Swain DP, High R, et al. Effect of intensity of aerobic training on $\mathrm{VO}_{2}$ max. Med Sci Sports Exerc 2008;40:1336-43.

72 Rakobowchuk M, Tanguay S, Burgomaster KA, et al. Sprint interval and traditional endurance training induce similar improvements in peripheral arterial stiffness and flow-mediated dilation in healthy humans. Am J Physiol Regul Integr Comp Physiol 2008:295:R236-42.

73 Tabata I, Nishimura K, Kouzaki M, et al. Effects of moderate-intensity endurance and high-intensity intermittent training on anaerobic capacity and VO2max. Med Sci Sports Exerc 1996;28:1327-30.

74 Edge J, Bishop D, Goodman C. The effects of training intensity on muscle buffer capacity in females. Eur J Appl Physiol 2006;96:97-105.

75 Dunham C, Harms CA. Effects of high-intensity interval training on pulmonary function. Eur J App/ Physiol 2012;112:3061-8.

76 Bayati M, Farzad B, Gharakhanlou R, et al. A practical model of low-volume high-intensity interval training induces performance and metabolic adaptations that resemble 'all-out' sprint interval training. J Sports Sci Med 2011:10:571-6.

77 Astorino TA, Allen RP, Roberson DW, et al. Effect of high-intensity interval training on cardiovascular function, V02max, and muscular force. J Strength Cond Res 2012:26:138-45.

78 Leggate M, Nowell MA, Jones SA, et al. The response of interleukin- 6 and soluble interleukin- 6 receptor isoforms following intermittent high intensity and continuous moderate intensity cycling. Cell Stress Chaperones 2010;15:827-33.

79 Maran A, Pavan P, Bonsembiante B, et al. Continuous glucose monitoring reveals delayed nocturnal hypoglycemia after intermittent high-intensity exercise in nontrained patients with type 1 diabetes. Diabetes Technol The 2010;12:763-8

80 Guelfi KJ, Jones TW, Fournier PA. The decline in blood glucose levels is less with intermittent high-intensity compared with moderate exercise in individuals with type 1 diabetes. Diabetes Care 2005:28:1289-94.

81 Keteyian SJ, Hibner BA, Bronsteen K, et al. Greater improvement in cardiorespiratory fitness using higher-intensity interval training in the standard cardiac rehabilitation setting. J Cardiopulm Rehabil Prev 2014;34:98-105.

82 Tjønna AE, Leinan IM, Bartnes AT, et al. Low- and high-volume of intensive endurance training significantly improves maximal oxygen uptake after 10-weeks of training in healthy men. PLOS ONE 2013;8:E65382. 
83 Rognmo $\varnothing$, Hetland E, Helgerud J, et al. High intensity aerobic interval exercise is superior to moderate intensity exercise for increasing aerobic capacity in patients with coronary artery disease. Eur J Cardiovasc Prev Rehabil 2004;11:216-22.

84 Wallman K, Plant LA, Rakimov B, et al. The effects of two modes of exercise on aerobic fitness and fat mass in an overweight Population. Res Sports Med 2009;17:156-70.

85 Tsekouras YE, Magkos F, Kellas Y, et al. High-intensity interval aerobic training reduces hepatic very low-density lipoprotein-triglyceride secretion rate in men. Am J Physiol Endocrinol Metab 2008;295:E851-8.

86 Freese EC, Gist NH, Acitelli RM, et al. Acute and chronic effects of sprint interval exercise on postprandial lipemia in women at-risk for the metabolic syndrome. J App/ Physiol 2015;118:872-9.

87 Gillen JB, Percival ME, Ludzki A, et al. Interval training in the fed or fasted state improves body composition and muscle oxidative capacity in overweight women. Obesity (Silver Spring) 2013;21:2249-55.

88 MacPherson REK, Hazell TJ, Olver TD, et al. Run sprint interval training improves aerobic performance but not maximal cardiac output. Med Sci Sports Exerc 2011:43:115-22.

89 Trilk JL, Singhal A, Bigelman KA, et al. Effect of sprint interval training on circulatory function during exercise in sedentary, overweight/obese women. Eur J Appl Physiol 2011;111:1591-7.

90 Kendall KL, Smith AE, Graef JL, et al. Effects of four weeks of high-intensity interval training and creatine supplementation on critical power and anaerobic working capacity in college-aged men. J Strength Cond Res 2009;23:1663-9.

91 Skleryk JR, Karagounis LG, Hawley JA, et al. Two weeks of reduced-volume sprint interval or traditional exercise training does not improve metabolic functioning in sedentary obese men. Diabetes Obes Metab 2013;15:1146-53.

92 Leggate M, Carter WG, Evans MJ, et al. Determination of inflammatory and prominent proteomic changes in plasma and adipose tissue after high-intensity intermittent training in overweight and obese males. J App/ Physiol 2012;112:1353-60.

93 Astorino TA, Allen RP, Roberson DW, et al. Adaptations to high-intensity training are independent of gender. Eur J Appl Physiol 2011;111:1279-86.

94 Hood MS, Little JP, Tarnopolsky MA, et al. Low-volume interval training improves muscle oxidative capacity in sedentary adults. Med Sci Sports Exerc 2011;43:1849-56.

95 Little JP, Gillen JB, Percival ME, et al. Low-volume high-intensity interval training reduces hyperglycemia and increases muscle mitochondrial capacity in patients with type 2 diabetes. J App/ Physiol 2011;111:1554-60.

96 Richards JC, Johnson TK, Kuzma JN, et al. Short-term sprint interval training increases insulin sensitivity in healthy adults but does not affect the thermogenic response to $\beta$-adrenergic stimulation. J Physiol (Lond) 2010:588:2961-72.

97 Whyte LJ, Gill JMR, Cathcart AJ. Effect of 2 weeks of sprint interval training on health-related outcomes in sedentary overweight/obese men. Metab Clin Exp 2010;59:1421-8.

98 Hosseinpanah F, Barzin M, Mirmiran P, et al. Effect of changes in waist circumference on metabolic syndrome over a 6.6-year follow-up in Tehran. Eur J Clin Nutr 2010;64:879-86.

99 Laforgia J, Withers RT, Gore CJ. Effects of exercise intensity and duration on the excess post-exercise oxygen consumption. J Sports Sci 2006;24:1247-64.

100 Boutcher SH. High-intensity intermittent exercise and fat loss. J Obes 2011;2011:868305.

101 Gratas-Delamarche A, Le Cam R, Delamarche P, et al. Lactate and catecholamine responses in male and female sprinters during a Wingate test. Eur I Appl Physiol Occup Physiol 1994;68:362-6.

102 Vincent $\mathrm{S}$, Berthon $\mathrm{P}$, Zouhal $\mathrm{H}$, et al. Plasma glucose, insulin and catecholamine responses to a Wingate test in physically active women and men. Eur J App/ Physiol 2004;91:15-21.

103 Collins S, Surwit RS. The $\beta$-adrenergic receptors and the control of adipose tissue metabolism and thermogenesis. Recent Prog Horm Res 2001;56:309-28.
104 Crampes F, Beauville $M$, Riviere $D$, et al. Effect of physical training in humans on the responses of isolated fat cells to epinephrine. J App/ Physiol 1986;61:25-9.

105 Krustrup P, Söderlund K, Mohr M, et al. Recruitment of fibre types and quadriceps muscle portions during repeated, intense knee-extensor exercise in humans. Pflugers Archiv Eur J Physiol 2004;449:56-65

106 Krustrup P, Söderlund K, Mohr M, et al. The slow component of oxygen uptake during intense, sub-maximal exercise in man is associated with additional fibre recruitment. Pflugers Archiv Eur J Physio/ 2004;447:855-66.

107 Yang J. Enhanced skeletal muscle for effective glucose homeostasis. Prog Mol Biol Trans/ Sci 2014;121:133-63.

108 McPherron AC, Guo T, Bond ND, et al. Increasing muscle mass to improve metabolism. Adipocyte 2013;2:92-8.

109 Srikanthan P, Karlamangla AS. Relative muscle mass is inversely associated with insulin resistance and prediabetes. Findings from the third National Health and Nutrition Examination Survey. J Clin Endocrinol Metab 2011;96:2898-903.

110 Gist NH, Fedewa MV, Dishman RK, et al. Sprint interval training effects on aerobic capacity: a systematic review and meta-analysis. Sports Med 2014;44:269-79.

111 Gibala M. Molecular responses to high-intensity interval exercise. App/ Physiol Nutr Metab 2009:34:428-32.

112 Slørdahl SA, Wang E, Hoff J, et al. Effective training for patients with intermittent claudication. Scand Cardiovasc J 2005:39:244-9.

113 Kiviniemi AM, Tulppo MP, Eskelinen JJ, et al. Cardiac autonomic function and high-intensity interval training in middle-age men. Med Sci Sports Exerc 2014:46:1960-7.

114 Vigen $\mathrm{R}$, Ayers C, Willis B, et al. Association of cardiorespiratory fitness with total, cardiovascular, and noncardiovascular mortality across 3 decades of follow-up in men and women. Circ Cardiovasc Qual Outcomes 2012;5:358-64.

115 Lee DC, Sui $X$, Artero EG, et al. Long-term effects of changes in cardiorespiratory fitness and body mass index on all-cause and cardiovascular disease mortality in men: the aerobics center longitudinal study. Circulation 2011;124:2483-90.

116 Seccareccia F, Pannozzo F, Dima F, et al. Heart rate as a predictor of mortality: the MATISS project. Am J Public Health 2001:91:1258-63.

117 Strandberg TE, Pitkala K. What is the most important component of blood pressure: systolic, diastolic or pulse pressure? Curr Opin Nephrol Hypertens 2003:12:293-7.

118 Taylor RS, Ashton KE, Moxham T, et al. Reduced dietary salt for the prevention of cardiovascular disease: a meta-analysis of randomized controlled trials (Cochrane review). Am J Hypertens 2011;24:843-53.

119 Pal S, Radavelli-Bagatini S, Ho S. Potential benefits of exercise on blood pressure and vascular function. J Am Soc Hypertens 2013;7:494-506.

120 Nishida K, Harrison DG, Navas JP, et al. Molecular cloning and characterization of the constitutive bovine aortic endothelial cell nitric oxide synthase. J Clin Invest 1992; 90:2092-6.

121 Green DJ, Maiorana A, O'Driscoll G, et al. Effect of exercise training on endothelium-derived nitric oxide function in humans. J Physiol (Lond) 2004:561:1-25.

122 Gibala MJ, McGee SL, Garnham AP, et al. Brief intense interval exercise activates AMPK and p38 MAPK signaling and increases the expression of PGC- $1 \alpha$ in human skeletal muscle. J Appl Physiol 2009;106:929-34.

123 Towler MC, Hardie DG. AMP-activated protein kinase in metabolic control and insulin signaling. Circ Res 2007;100:328-41.

124 Horowitz JF, Klein S. Lipid metabolism during endurance exercise. Am J Clin Nutr 2000;72:S558-63.

125 Paoletti R, Bolego C, Poli A, et al. Metabolic syndrome, inflammation and atherosclerosis. Vasc Health Risk Manag 2006;2:145-52.

126 Libby P. Inflammation and cardiovascular disease mechanisms. Am J Clin Nutr 2006;83:S456-60

127 Olefsky JM, Glass CK. Macrophages, inflammation, and insulin resistance. Annu Rev Physiol 2010;72:219-46.

128 Fischer CP. Interleukin-6 in acute exercise and training: what is the biological relevance? Exerc Immunol Rev 2006;12:6-33. 